\title{
Incidence of renal carcinoma in non-functioning kidney due to renal pelvic stone disease
}

\author{
KURSAD ZENGIN $^{1}$, SERHAT TANIK ${ }^{1}$, NEVZAT CAN SENER ${ }^{2}$, \\ SEBAHATTIN ALBAYRAK ${ }^{1}$, MUSA EKICI ${ }^{3}$, IBRAHIM HALIL BOZKURT ${ }^{4}$, \\ HASAN BAKIRTAS $^{1}$, MESUT GURDAL ${ }^{1}$ and MUHAMMED ABDURRAHIM IMAMOGLU ${ }^{1,5}$ \\ ${ }^{1}$ Department of Urology, Faculty of Medicine, Bozok University, 66200 Yozgat; ${ }^{2}$ Department of Urology, \\ Numune Education and Research Hospital, 01010 Adana; ${ }^{3}$ Department of Urology, Faculty of Medicine, \\ Hitit University, 19100 Corum; ${ }^{4}$ Department of Urology, Bozyaka Education and Research Hospital, 35140 Izmir; \\ ${ }^{5}$ Department of Urology, Diskapi Yildirim Beyazit Education and Research Hospital, 06110 Ankara, Turkey
}

Received February 4, 2015; Accepted April 15, 2015

DOI: $10.3892 / \mathrm{mco} .2015 .550$

\begin{abstract}
The objective of this study was to report our pathological findings in nephrectomy specimens from patients treated for non-functioning hydronephrotic kidney due to renal pelvic stone disease. A total of 97 patients who underwent nephrectomy for non-functioning hydronephrotic kidneys between January, 2011 and June, 2014 were retrospectively reviewed. A non-functioning kidney was defined as one having paper-thin parenchyma on urinary ultrasound or computed tomography, exhibiting no contrast visualization in the collecting duct system on intravenous urography and having a split renal function of $<10 \%$ on nuclear renal function studies. Following pathological evaluation, 9 patients were diagnosed with xanthogranulomatous pyelonephritis, 9 with malignant tumors and 79 with chronic pyelonephritis. Of the patients with chronic pyelonephritis, 2 also had renal adenomas. The malignant tumors included 3 transitional cell carcinomas (TCC), 2 squamous cell carcinomas (SCC), 3 renal cell carcinomas (RCC) (1 sarcomatoid, 1 papillary and 1 clear cell RCC), whereas 1 patient had concurrent RCC and TCC. In conclusion, non-functioning kidneys, particularly those with kidney stones, should be managed as possible malignancies, due to the higher incidence of malignant tumors in such patients compared with the normal population.
\end{abstract}

\section{Introduction}

Smoking, high consumption of fatty foods, hypertension, diabetes mellitus, obesity and decreased physical activity are

Correspondence to: Dr Kursad Zengin, Department of Urology, Faculty of Medicine, Bozok University, 118 Medrese Mahallesi Adnan Menderes Bulvari, 66200 Yozgat, Turkey

E-mail: kursadzengin@gmail.com

Key words: non-functioning kidney, renal carcinoma, renal stone considered to be risk factors for renal carcinoma (1). Chronic inflammation has been proven to promote tumor growth (2). The effect of chronic irritation on different types of cancer has been previously demonstrated $(3,4)$.

Bladder cancer is known to be caused by the chronic inflammation associated with the presence of bladder stones (5), which results in neoplastic differentiation (6).

Chronic kidney stone disease may lead to loss of kidney function and subsequent nephrectomy. Chronic kidney stone disease has been shown to be associated with transitional cell carcinoma (TCC) or renal cell carcinoma (RCC) and kidney tumors have been found to be more frequent among patients with kidney stones (7-9). The number of studies and case reports reporting tumors in specimens from patients undergoing nephrectomy for non-functioning kidney due to kidney stones is limited (10). Discriminating between benign conditions and malignancies may be difficult in non-functioning kidneys unless nephrectomy is performed, as reported in the literature (11).

In this study, we aimed to report our pathological findings in nephrectomy specimens from patients treated for non-functioning hydronephrotic kidney due to renal pelvic stones.

\section{Patients and methods}

Patients. Between January, 2011 and June, 2014, a total of 97 patients underwent nephrectomy for non-functioning hydronephrotic kidney due to renal pelvic stones at the Departments of Urology of Bozok University and Diskapi Education and Research Hospital, Turkey. The pathology reports and patient data were retrospectively reviewed.

This study's protocol was approved by the Local Ethics Committee of Bozok University (604/01-2014).

Definition of non-functioning kidney. A non-functioning kidney was defined as one having paper-thin parenchyma on urinary ultrasound or computed tomography, exhibiting no contrast visualization in the collecting duct system on intravenous urography and having a split renal function of $<10 \%$ on nuclear renal function studies. 
Follow-up. The patient follow-up included urinary ultrasound at 1 and 3 months postoperatively and, if necessary, computed tomography or magnetic resonance imaging.

\section{Results}

Patient characteristics. A total of 97 patients underwent nephrectomy for non-functioning hydronephrotic kidney due to renal pelvic stone disease. The mean patient age was $61.98 \pm 9.6$ years. Of the 97 patients, 40 were female and 57 were male. Of the affected kidneys, 54 were on the right and 43 on the left side.

Pathological diagnosis. Following pathological evaluation, 9 patients were diagnosed with xanthogranulomatous pyelonephritis, 9 with malignant tumors and 79 with chronic pyelonephritis. Among the patients with chronic pyelonephritis, 2 also had renal adenomas.

The malignant tumors included 3 TCCs, 2 squamous cell carcinomas (SCCs), 3 RCCs (1 sarcomatoid, 1 papillary and 1 clear cell RCC), whereas 1 patient had concurrent RCC and TCC. The pathological diagnosis of the patients is summarized in Table I.

Follow-up. The patients were followed up for a mean of 1.4 years (range, 6 months- 3 years). The patients with TCC underwent ureterectomy and bladder cuff excision as an adjuvant operation. One patient required further treatment due to metastatic disease and eventually succumbed to the disease after 11 months. A total of 3 patients required adjuvant chemotherapy and the remaining patients were disease-free at the last follow-up.

\section{Discussion}

In functional kidneys, renal tumors may mimic urolithiasis and renal colic pain; therefore, they may be easier to diagnose. However, this may not be the case for non-functioning kidneys. In functioning kidneys, normal blood flow may be visualized by contrast-imaging studies, unlike non-functioning kidneys (12). Therefore, tumors in non-functioning kidneys may be harder to diagnose. For the treatment of a non-functioning kidney, simple nephrectomy is usually performed. The estimated age-standardized renal carcinoma incidence per 100,000 individuals is 15.8 for men and 7.1 for women in Europe (13). However, the pathological evaluation revealed an incidence of malignancies of $9.3 \%$ in our study.

Patients appear to be prone to SCC following years of inflammation in the urinary tract caused by stone disease (14). There are several reports published on bladder stones and SCC $(15,16)$, although SCC associated with kidney stones appears to be less frequent (17). This may be due to the lack of stasis in the renal pelvis compared to the bladder (18). Under conditions of stasis, such as in cases with hydronephrotic non-functioning kidneys, the rate of SCC appears to increase. In a study by Shah et al (19), the authors reported 2 cases of untreated/neglected renal stones and suggest the stones to be the cause of malignancy.

Several case reports have been published regarding non-functioning kidneys with kidney stones and SCC. Mathur et al (17) reported a case of renal SCC presenting as
Table I. Pathological diagnosis in specimens of nephrectomy for non-functioning kidney due to renal pelvic stones.

\begin{tabular}{lcc}
\hline $\begin{array}{l}\text { Pathological } \\
\text { diagnosis }\end{array}$ & Patient no. & $\begin{array}{c}\text { Patient age, yrs } \\
(\text { mean } \pm \text { SD })\end{array}$ \\
\hline $\begin{array}{l}\text { Chronic } \\
\text { pyelonephritis }\end{array}$ & $79^{\mathrm{a}}$ & $57.8 \pm 8.7$ \\
$\begin{array}{l}\text { Xanthogranulomatous } \\
\text { pyelonephritis }\end{array}$ & 9 & $59.2 \pm 7.2$ \\
$\begin{array}{l}\text { Malignant tumors } \\
\text { TCC }\end{array}$ & 3 & \\
RCC & 3 & $60.1 \pm 10.3$ \\
SCC & 2 & $63.4 \pm 7.6$ \\
RCC + TCC & 1 & $64.6 \pm 4.5$ \\
\end{tabular}

a2 patients also had renal adenomas. SD, standard deviation; TCC, transitional cell carcinoma; RCC, renal cell carcinoma; SCC, squamous cell carcinoma.

a multicystic mass. Verma et al (20) presented a case of SCC and kidney stones and reported the low incidence of this tumor in non-functioning kidneys. In our study, 2 of the 97 patients (2\%) had SCC in a non-functioning kidney and both cases were associated with kidney stones, similar to the available literature.

In 2007, Yeh et al (12) published their series of 47 patients undergoing nephrectomy for non-functioning kidneys with concurrent stone disease/chronic infection. In that study, $\sim 51 \%$ of the patients were diagnosed with malignancy postoperatively, although preoperative imaging studies suggested possible malignancy in only $15 \%$ of the cases. The tumors included 17 TCCs, 5 RCCs, 1 SCC and 1 epidermoid carcinoma. There were 5 reported deaths during follow-up. In our study population of 97 patients, the pathological examination revealed 9 malignant tumors (9.3\%), namely 3 TCCs, 2 SCCs, 3 RCCs and 1 case of concurrent RCC and TCC.

The limitations of the present study were its retrospective method and relatively small cohort.

In conclusion, non-functioning kidneys, particularly those with kidney stones, should be managed as a possible malignancies, due to the the higher incidence of malignant tumors in such patients compared with the normal population. Prospective studies designed on larger cohorts are required to confirm these findings.

\section{References}

1. Washio M, Mori M, Mikami K, et al: Cigarette smoking and other risk factors for kidney cancer death in a Japanese population: Japan Collaborative Cohort Study for evaluation of cancer risk (JACC study). Asian Pac J Cancer Prev 14: 6523-6528, 2014.

2. Unal M, Tamer L, Ateş NA, Akbaş Y, Pata YS, Vayisoğlu Y, Ercan B, Görür K and Atik U: Glutathione S-transferase M1, $\mathrm{T} 1$ and $\mathrm{P} 1$ gene polymorphism in laryngeal squamous cell carcinoma. Am J Otolaryngol 25: 318-322, 2004.

3. Jongthawin J, Techasen A, Loilome W, Yongvanit P and Namwat N: Anti-inflammatory agents suppress the prostaglandin E2 production and migration ability of cholangiocarcinoma cell lines. Asian Pac J Cancer Prev 13 (Suppl): 47-51, 2012. 
4. Guo YZ, Pan L, Du CJ, Ren DQ and Xie XM: Association between C-reactive protein and risk of cancer: A meta-analysis of prospective cohort studies. Asian Pac J Cancer Prev 14: 243-248, 2013

5. Kobeissi LH, Yassine IA, Jabbour ME, Moussa MA and Dhaini HR: Urinary bladder cancer risk factors: A Lebanese case-control study. Asian Pac J Cancer Prev 14: 3205-3211, 2013.

6. Chung SD, Tsai MC, Lin CC and Lin HC: A case-control study on the association between bladder cancer and prior bladder calculus. BMC Cancer 13: 117, 2013.

7. Saw KC, Ball RY, Khan NH, Pilling JR, Eardley I and Ashken MH: Renal cell carcinoma with osteosarcomatous differentiation simulating staghorn calculus: A case report and literature review. J Urol 151: 1607-1609, 1994.

8. Arisawa C, Fujii Y, Higashi Y, Owada F, Shimizu S and Kaneko K: Pelvic kidney associated with staghorn calculus and renal pelvic cancer: A case report. Hinyokika Kiyo 41: 209-211, 1995 (In Japanese).

9. Ansari MS, Singh I and Gupta NP: Renal stone masquerading as an occult renal cell cancer (incidental RCC). Int Urol Nephrol 36 235-237, 2004

10. Sisodia SM, Khan WAZA and Bhavsar SP: Incidental primary papillary mucinous adenocarcinoma of the renal pelvis in a case of non-functioning kidney due to chronic pyelonephritis and pelvic calculus. Saudi J Kidney Dis Transpl 23: 592-593, 2012.

11. Khalid S, Zaheer S, Zaheer S, Ahmad I and Mohd Khalid: Xanthogranulomatous pyelonephritis: Rare presentation of a rare disease. South Asian J Cancer 2: 4, 2013.

12. Yeh CC, Lin TH, Wu HC, Chang $\mathrm{CH}$, Chen $\mathrm{CC}$ and Chen WC: A high association of upper urinary tract transitional cell carcinoma with nonfunctioning kidney caused by stone disease in Taiwan. Urol Int 79: 19-23, 2007.
13. Levi F, Ferlay J, Galeone C, Lucchini F, Negri E, Boyle P and La Vecchia C: The changing pattern of kidney cancer incidence and mortality in Europe. BJU Int 101: 949-958, 2008.

14. Hui Wu J, Xu Y, Qiang Xu Z, Yang K, Qiang Yang S and Shun Ma H: Severe anemia and melena caused by pyeloduodenal fistula due to renal stone-associated squamous cell carcinoma. Pak J Med Sci 30: 443-445, 2014.

15. Rajaian S, Kumar RM and Kekre NS: Squamous cell carcinoma associated with large bladder calculus. ANZ J Surg 82: 92-93, 2012.

16. Cho JH and Holley JL: Squamous cell carcinoma of the bladder in a female associated with multiple bladder stones. BMC Res Notes 6: 354, 2013

17. Mathur S, Rana P, Singh S, Goyal V and Sangwan M: Incidentally detected squamous cell carcinoma in non-functioning kidney presenting as multi-cystic mass. J Surg Case Rep 2011: 8, 2011.

18. Jarrett TW, Chen Y, Anderson AE, Oshinsky G, Smith AD and Weiss GH: Model of human transitional cell carcinoma: Tumor xenografts in upper urinary tract of nude rat. J Endourol 9: 1-7, 1995 .

19. Shah HN, Jain P and Chibber PJ: Laparoscopic nephrectomy for giant staghorn calculus with non-functioning kidneys: Is associated unsuspected urothelial carcinoma responsible for conversion? Report of 2 cases. BMC Urol 6: 1, 2006.

20. Verma N, Yadav G, Dhawan N and Kumar A: Squamous cell carcinoma of kidney co-existing with renal calculi: A rare tumour. BMJ Case Rep 2011: pii: bcr1020103388, 2011. 